\title{
A Smart Shopping System for Visually Impaired
}

\author{
V. Lobo, R.Prabhu, Polu Bal Kumar Reddy
}

\begin{abstract}
Recently researches and many developments were going in the field of automation and embedded systems to develop and reduce the work of the manpower in industry as well as in public domain areas like Railway station (automatic ticket collection), Metro bus (online reservation), Flight (Auto Pilot mode) etc. To develop more Automation in and to help the blind people, old age and handicapped person we proposed a technique named as automatic trolley carrier navigation and the billing system. This method can be implemented in all shopping malls, big clothing shop, house hold appliances shops etc. It avoids the people to stand in a big queue and automatic billing can be done. Moreover it helps blind people, old age people, Handicapped Persons in the shopping malls make them to purchase in shopping malls by informing about the location of the product, quantity, price and automatic billing etc. The arrangement of the trolley consists of the robotic structure and servo motor which makes the trolley tonavigate and tell way of location of the product availability and price based on the user input. Theuser gives the command through the Bluetooth. Then the keypad passes the customer product information to the Micro-controller then the trolley moves automatically. The use of RFID reader is to scan theEPIC tag ID of allproducts to Identifythe name, price, Quantity of the products. Depending on the RF signal from the RFID -reader, it passes the information to the micro controller and from that it identify the product and display the name, Quantity, price of the each product in the LCD display. The ultrasonic sensor is used to detect the any obstacles as well as the object.
\end{abstract}

Key words: RFID, Ultra sonic sensor, DC servo motor and

\section{INTRODUCTION}

Shopping mall people can find all different varieties of dresses, House hold items, different varieties of foods, vegetables and electrical appliances. Many persons like working woman, men every one will show more interest in shopping. for blind persons, handicapped persons, old age shopping is the difficult task for them inside the shopping malls. Because they don't know the location of the product, whether it is available or not, current offers, they feel tired to stand in a queue for billing. So, they want others Persons to find the location, to navigate way inside the shopping mall, billings. Due to increase in population in people requirements also increased and in our modern world government is also suggesting for smart city development. And Now day's as small shopping mallsalso increased and present in every location to cater the needs of the people.In

Revised Manuscript Received on September 10, 2019.

Prof. Dr.V. Lobo, Professor-Dept. of Chemistry, Aurora Scientific Technological Research Academy, Bandlaguda, Hyderabad, Telangana, India.

(E-mail: Profvlobo1@gmail.com)

R.Prabhu, AP/ECE, Electronics and Communication Engineering, Sri Shanmugha College of Engineering and Technology, Puthur, Tamil Nadu, India.

(E-mail: vlsiprabhu@outlook.com)

Polu Bal Kumar Reddy, AP/ECE, Electronics and Communication Engineering, Pallavi Engineering college, Ranga Reddy district, Hyderabad, Telangana, India.

(E-mail: balureddy5586@gmail.com) Bluetooth.

shopping mall for every day the price of the product like rice, fruit, vegetables, house hold thing etc changes from day to day so continuous updating is required in Automatic billing system to improve the customer satisfaction and provides good shopping experience to all customers. sometimes customers may face issue in the shopping mall due to non-availability of product information, price, quantity in that situation it takes more time to solve the problem in the bill counter to overcome all these problems stated above in shopping mall.we have Proposed a new method named as automatic trolley carrier navigation and the billing system. It solves all the issues faced by the customer

This can be done by creating a common cloud-based environment all the product details location, price, quantity will be stored in the cloud database and in the Trolley, it is connected with the server inside the shopping mall. Trolley consist of simply a RFID reader, Micro-controller, transmitting antenna and a LCD display.This automatic trolley helps the Handicapped, blind persons and normal persons at the time of shopping. In this system customer can hold a Bluetooth head set to query about the product and this query information is passed to the micro-controller and then it gives the brief information about product price and name etc.

In this proposed method the customer take the ' $\mathrm{N}$ ' number of different product and place inside the trolley means it automatically identify the price and it displays the product details such as name, price, quantity and total price value. The proposed system is effectively designed by considering above aspects of mind. In this method we preferred ATMEGA 8 microcontroller to perform the smart operation in automatic shopping

\section{EXISTING SYSTEM}

Originally the architecture to build aautomatic itemidentification in network commenced at the former Auto-ID Center, now the Auto-ID Labswith the process ofstandardization issues currently managed by EPCglobal Inc.The Auto-ID Centre mottois to create a smart automatic intelligent Environment systemwhich automatically identify the price, specification and all details of the product. It creates an Electronic virtual reality visionto blind and handicapped Person for smart shopping. The creation of the smart automaticintelligent environment infrastructure identifies the demandes to identify objects automatically anduniquelyubiquitous computing system leveraging the internet for global connectivity. In existing method, they use bar code readers and bar code scanners to identify the product once if the bar code is not clear it cannot identify the product. In day to day products also increasing from 
different vendors so its difficult to create a unique id for each product using barcode. The components forming the intelligent infrastructure arecommonly referred to as an EPC identification Network where the term EPC (Electronic Product Code) is a result of the unique object identification system.

By using the EPC unique ID present in RFID tag will provides automatic Identification of Physical Quantities and it intimates to blind persons through the voice message and it will display the name, price, specification of the product in LCD Display. Here we are using a WISP RFID reader it is a battery free platform for sensing and computation, it has 16-bit flash microcontroller, wireless power supply, low power UHF communication RFID reader. We have implemented UHF-RFID powered and red-light sensor, temperature sensor, accelerometer, and strain gauge.

\section{BLOCK-DIAGRAM}

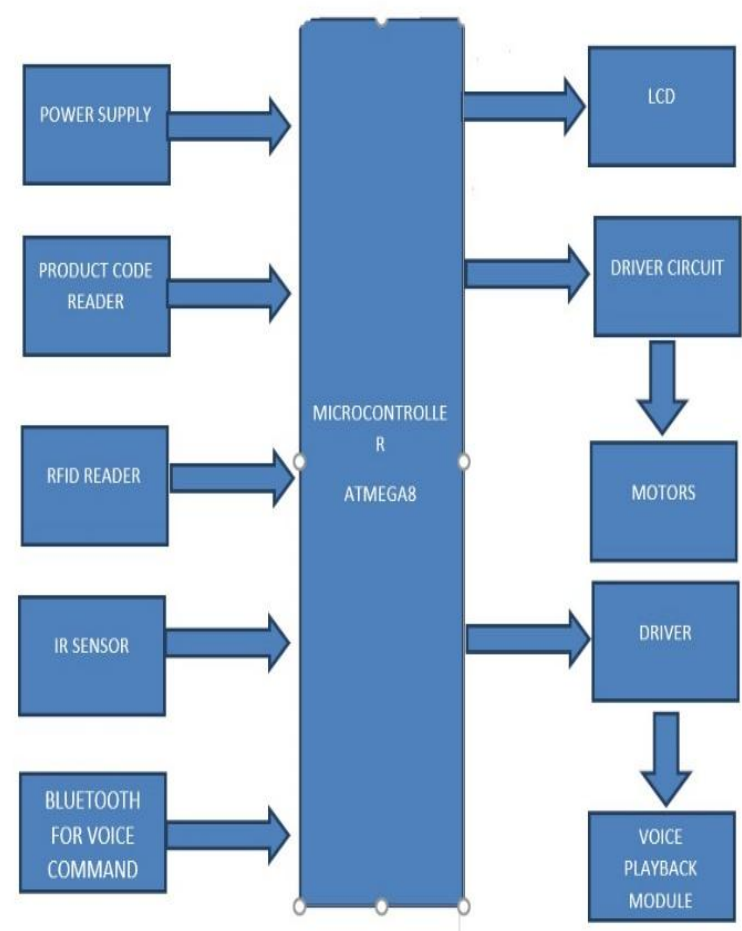

IV. PROPOSED METHOD:

Our proposed method introduces the trolley moves automatically. The structure of the trolley consists of the robotic structure.The proposed method has Ultrasonic Sensors to find the length and distance of target product materials. through the air medium using wireless sensor technology. The DC servo motor is attached to the trolley, which is used to move the robot to reach the exact location of

the product in the shopping mall . The keypad is used to select the products, when the user selects any products through keypad it give the commands to the controller and make the robotic trolley move on to the exact location.

The purpose of product code reader is a hand-held input device used to capture and read information contained in the product RFID-tag.
Depending on the product information signal from the Product ID -reader, the controller displays the price of each product in the LCD display. The proposed system has the feature of automatic billing when a customer carries a trolley full of items through RFID antennas. The WISP RFID reader antenna will scan the multiple UHF - RFID tag's and from the tag it get the unique EPC code, with that code it will identify the product price and generates the bill Automatically

\section{WORKING PRINCIPLE}

Here the RFID technology is mainly used. The RFID tag is attached to the product and RFID reader is attached to the trolley. RFID tag is used instead of barcode. It will be directly read by the trolley. Then trolley is automatically moved in customer requirements. DC power supply to supply voltage to each block.

Customer said the product name through the Bluetooth after the trolley moves automatically. Then the product price and details are displayed by the LCD. And also the product details are given through the voice playback module. Then the ultrasonic sensor is used for obstacle detection. It helps the blind to navigate inside the supermarket.

Here the battery is the power source for the entire block or devices. The microcontroller acts as the central processing unit. Here we have used the Atmel microcontroller ATmega8 .The infrared sensor is used find the path and the circuitry for finding the correct path is built and interfaced with the microcontroller.

The Bluetooth module acts as the communication device between the microcontroller ATmega8 and the user's mobile phone.

and closing of basket lid is done by a servo motor. When the product is dropped into cart the product details will be added to the bill.

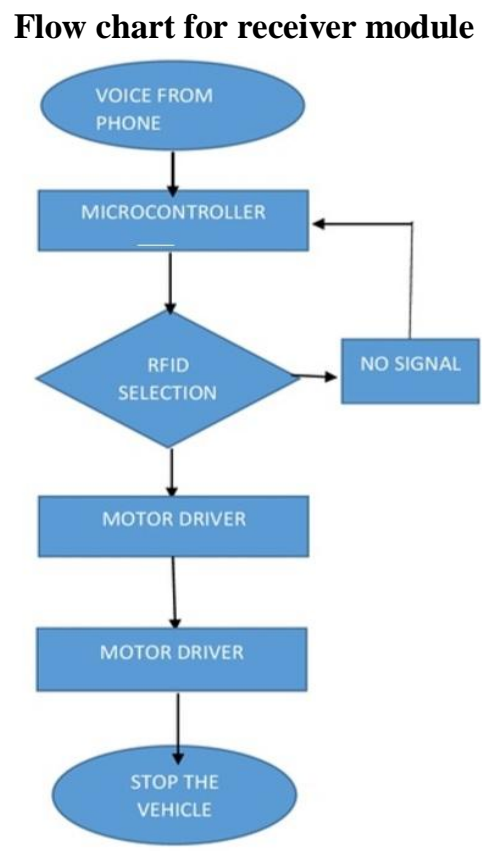


At same time by pressing remove switch the basket lid will be open so that the person can take back the product. And the amount of the product will be deducted from the bill. So that the person can decide whether to add or remove the product.

Finally the shopkeeper can access every details of purchase and also details of remaining products in the shop using website. And finally billing can be done within the cart itself.

\section{IMPLEMENTATION PLATFORM}

Hardware Requirements:

$\begin{array}{ll}\text { - } & \text { Battery } \\ \text { - } & \text { Microcontroller - AT mega 8A } \\ \text { - } & \text { Infrared sensor } \\ \text { - } & \text { Rfid reader } \\ \text { - } & \text { Bluetooth } \\ \text { - } & \text { Voice play board } \\ \text { - } & \text { Speaker } \\ \text { - } & \text { Motor driver } \\ \text { - } & \text { motor }\end{array}$

Software Requirements:

- Platform - AVR STUDIO

- $\quad$ Compiler - Win AVR

\section{Advantages}

Unique product identification and it provides complete data collection like price ,name, quantity using the RFID tag placed in the product.

RFID is placed in 5 major terminal places:

- Access Control

- Billing section

- $\quad$ product Identification and Location

- location Tracking

- customer relationship grievance counter.

The above RFID application will give importance to a terminal port officers as a Direct services or as Extra service. It simplifies the government Security regulations and record maintains requirements.

\section{RESULT}

$\checkmark \quad$ The main aim was to design and build a prototype and implementation of a shopping trolley for blind people. The hardware and software were well integrated together.

The hardware is able to detect the obstacles and RFID reader reads the product details.

Voice system is also enabled such that all the details of the product can be heard through Bluetooth. Billing system is also automated.

\section{CONCLUSION}

The proposedsmart automatic trolley carrier navigation and billing system intent to help blind people handicapped, old age and normal customer in the billing process, product cost, price and quantity identification ,Automatic tracking using cloud based RF-ID technique performs efficient and execellent in the shopping mall and reduces all the burdens
- In System Programmer - ProgISP 172

faced in the existing method. In day to day life the product cost also increases and decreases it makes the system database to be updated frequently. The proposed method finally created a practical electronic virtual reality vision to the blind people in the shopping mall.

\section{REFERENCES}

1 Dr. P. MuthuKannan,AnupriyaAsthana, "Automatic Retail System Using RFID”, Volume 1, Issue 5, October 2013, International Journal of Advance Research in Computer Science and ManagementStudies.

2 Zeeshan Ali, ReenaSonkusare, "RFID Based Smart Shopping and Billing", International Journal of Advanced Research in Computer and Communication Engineering Vol. 2, Issue 12, December 2013

3 Raju Kumar, K. Gopalakrishna, K. Ramesha, "Intelligent Shopping Cart", International Journal of Engineering Science and Innovative Technology (IJESIT) Volume 2, Issue 4, July 2013.

4 SatishKamble, SachinMeshram, Rahul Thokal, RoshanGakre, "Developing a Multitasking Shopping Trolley Based On RFID Technology", International Journal of Soft Computing and Engineering (IJSCE) ISSN: 2231-2307, Volume-3, Issue-6, January 2014

5 VarshaJalkote , Alay Patel, VijayaGawande, Manish sBharadia, Gitanjali R. Shinde, Aaradhana A Deshmukh "Futuristic Trolley for Intelligent Billing with Amalgamation of RFID and BLUETOOTH ", International Journal of Computer Applications (0975 8887) International Conference on Recent Trends in engineering \& Technology - 2013(ICRTET'2013)

6 J.S.Awati, S.B.Awati, "Smart Trolley in Mega Mall", International Journal of Emerging Technology and Advanced Engineering (ISSN 2250-2459, Volume 2, Issue 3, March 2012)

7 Dr.K.V.K.K.Prasad, "Embedded/Real time operating systems",. Dreamtech Publications 2010 Edition.

8 Mingyan Li, , Rainer Falk paper on "multi-domain access control using asymmetric key based tag reader mutual authentication", Dreamtech Publications 2012 Edition.

9 http://www.rfidjournal.com

10 http://en.wikipedia.org/wiki/Bluetooth

11 D.V.S Chandra Babu, "wireless intelligent billing trolley for supermarket", International Journal of Advanced Research in Technology, vol.3, issue 1, Aug. 2012.

12 KamranAhasan,Paul Kingston IEEE paper on "rfidapplications:an introductory and exploratory study".

13 Mingyan Li, RadhaPoovendran, Rainer Falk paper on "multi-domain access control using asymmetric key based tag reader mutual authentication.

\section{AUTHORS PROFILE}

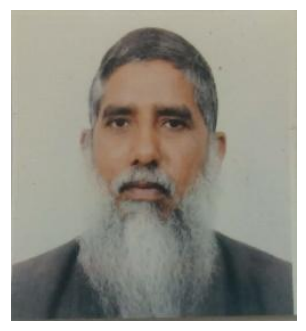

Prof. V. Lobo did his graduation (B.Sc.) post-graduation (M.Sc.) and doctoral (Ph.D.) research from the University of Bombay, Bombay. He did his doctoral research with a Minor Research Project awarded by the University Grants Commission (UGC), New Delhi. The topic of his research was "Separation of some elements using ionexchangers and neutron activation analysis". He has also completed a research project sponsored by the University of Bombay. He has presented several research papers in various conferences in India and abroad. He has published six research papers in journals of national and international 
repute. He has visited several countries such as Austria, Qatar, Slovakia, Turkey, USA and Yemen for Symposia / Seminar /Educational activities. $\mathrm{He}$ is a member of the Royal Society of Chemistry, UK, and Chemical Society of Ethiopia.Currently he is serving as Professor of Chemistry in ASTRA, Moosarambagh, Hyderabad. He teaches engineering chemistry, environmental science and soft skills to B.Tech students as Professor of Chemistry. He has also taught Instrumental Methods I, Instrumental Methods II in Modular Programme of European Credit Transfer System. He has also been assigned teach post-graduate students in chemistry. I have completed National Programme on Technology Enhanced Learning courses in chemistry, soft-skills, Intellectual Property Rights and Leadership.

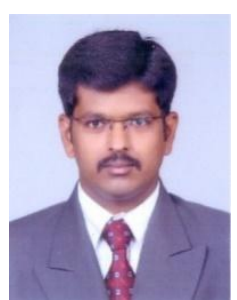

R.PRABHU received B.E degree in ECE department from Anna University Chennai and M.E degree in VLSI Design from Anna University Chennai, currently working as Assistant Professor in the Department of ECE, SSCET Salem, Completed Professional Development Course in "VLSI Design and Verification in Bangalore, technical expertise in Analog \& Mixed Signal Circuit Design, Digital Design, Microprocessors, Microcontrollers \& Interfacing, Embedded Systems, FPGA Based System Design, Low Power CMOS VLSI Design. His research interest in Static Timing Analysis (STA), FSM based design, low power circuit design, and system-on-chip design.

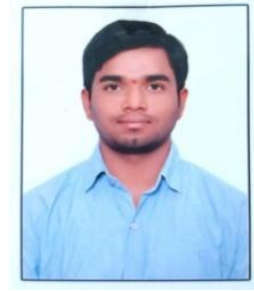

POLU BAL KUMAR REDDY received B.Tech degree in ECE from JNTU Hyderabad and M.Tech degree in VLSI system Design from JNTU Hyderabad. Currently working as an Assistant Professor in the Department of ECE, Pallavi Engineering College, Hyderabad .Areas of interests are VLSI, Digital electronics, embedded systems, Processors \& Controllers 